\title{
Use of Imported Inputs and the Cost of Importing: Evidence from Developing Countries
}

\author{
Mohammad Amin* and Asif Islam**
}

For a representative sample of manufacturing firms in 26 countries, the paper shows that changes in the cost of importing over time is significantly and negatively correlated with changes in the percentage of firm's material inputs that are of foreign origin. Furthermore, we show that there may be a non-linear relationship between import costs and imports. These findings are important as recent studies point towards a significant positive effect of imported inputs on productivity and growth. We hope that the present paper inspires more work on the determinants of imported inputs usage especially in developing countries.

Keywords: Imports, Trade Barriers, Cost of Importing, Trade Policy JEL: F14, F16, O14, O57

*Corresponding author, Enterprise Analysis Unit, World Bank, Washington DC, 20433. Email: mamin@worldbank.org.

** Enterprise Analysis Unit, World Bank, Washington DC, 20433. Email:
asif.m.islam@gmail.com




\section{Introduction}

Recent evidence suggests that the use of imported or foreign intermediate inputs contributes positively to the growth and development of economies (Amiti and Konings, 2007; Bernard et al., 2007; Seker, 2012). This may be because foreign inputs have superior embedded technology or because certain foreign and domestic inputs are imperfect substitutes (Halpern et al., 2009; Gibson and Graciano, 2011). ${ }^{1}$ However, existing evidence on the determinants and effects of foreign inputs is still relatively unexplored.

Using a repeated cross section of manufacturing firms across 26 developing countries with available data, we analyze how the percentage of a firm's material inputs that are of foreign origin (henceforth, foreign inputs) varies with the cost of importing as measured by the World Bank's Doing Business project. This is a first step towards understanding the connection between foreign inputs usage and trade policy design. We note that our estimation method involves regressing changes over time in import costs and foreign inputs (figure 1) and therefore it is less likely to suffer from endogeneity problems that plague pure cross-country regressions.

Our results reveal a statistically significant and economically large negative relationship between import costs and foreign inputs. For example, in Rwanda, which witnessed the largest increase in import costs from $\$ 4000$ to $\$ 4990$ between 2006 and 2011 in our sample, estimates suggest that the associated decline in foreign inputs equaled a large 15.8 percentage points (from 52 to 36.2 percent). We also find that the relationship between import costs and foreign inputs is non-linear being much stronger (more negative) at relatively lower values of import costs. Hence, even countries with relatively low import costs could benefit substantially via increased use of foreign inputs from further reductions in the import costs.

\footnotetext{
${ }^{1}$ For a literature review, see for example Wagner (2012).
} 
The contributions of this study are twofold. First, we establish the relationship between imports costs and the use of foreign inputs and estimate its size. Second, we use cross-country comparable firm level datasets based on common sampling methodology. We hope that the results of the paper will aid policy makers in boosting foreign inputs usage and thereby growth.

\section{Data and main variables}

Our main data source is a stratified random sample of about 14,000 manufacturing firms across a repeated cross-section of 26 developing countries provided by the World Bank's Enterprise Surveys (ES) between 2004 and 2011. ${ }^{2}$ These surveys are representative of the private nonagricultural economy and they are comparable across countries as well as over time.

The dependent variable is the percentage of a firm's material inputs that are of foreign origin (Imports) which is obtained from ES. The sample mean value of Imports equals 36.4 and the standard deviation is 37.4. Averaged across the two time periods, use of imported inputs is highest in Albania (64.8 percent) and lowest in Mexico (15.1 percent). Previous work using the same dependent variable includes for example, Amin and Islam (2014).

Our main explanatory variable is a measure of cost to import provided by Doing Business, World Bank. The variable is defined at the country level and captures costs (in USD and for a standardized container) associated with all procedures required to import goods, including documents, administrative fees for customs clearance and technical control, customs broker fees, terminal handling charges and inland transport (Import Cost). The mean value of Import Cost is 1,733 and the standard deviation of 1,000. As figure 1 shows there is substantial variation over time in Imports and Import Cost to allow for proper estimation.

\footnotetext{
${ }^{2}$ For each country in our sample, data are available for two rounds conducted at two different points of time. For the first round, data were collected in 2004 for 11 countries, 2005 for 11 countries and 2006 for 4 countries. The second round was conducted in 2008 for 11 countries, 2009 for 11 countries, 2010 for 3 countries and 2011 for 1 country.
} 
We address possible omitted variable bias by controlling for a number of variables. First, we control for all time-invariant country specific factors using country dummies (country fixed effects) and time specific global factors using a dummy variable that equals 1 for the latest round of the survey and 0 for the earlier round (Time). Second, we control for time varying country level variables that are known to be correlated with trade openness including (log of) GDP per capita, PPP adjusted (constant 2005 International dollars) taken from World Development Indicators (WDI), World Bank (Income); the weighted average of tariff rates (percent) across all products taken from WDI (Tariff rate); and the Heritage Foundation's measure of trade openness - Trade Freedom index. We note that in order to expand coverage of tariff rates and the trade freedom index, we take the average values of these variables over 2 or 3 years (depending on data availability) prior to the survey years for each country. Third, we control for time-varying firm-level variables from ES that may be correlated with Import Cost as well as Imports. These include (log of) total number of permanent employees (firm-size), (log of) age of the firm, a dummy equal to 1 if the firm were inspected during the year prior to the survey and 0 otherwise (Inspected) and the average level of severity on 0-4 scale (higher values imply greater severity) of the following constraints to the current operations of the firm: tax rates, tax administration, obtaining licenses and permits and corruption.

\section{Results}

Baseline results are presented in Table 1 . Column 1 provides a parsimonious OLS estimation of the relationship between imports and the costs to import with country fixed effects and the time variable. The estimated coefficient value of Import Cost equals -0.016, significant at less than 1 percent level. Adding the controls listed above does not change the qualitative nature of the 
results - the estimated Import Cost coefficient remains negative and significant at less than the 1 percent level (column 2-6). The coefficient value increases (in absolute terms) from -0.016 above to -0.021 (column 6) with all controls included. Thus, an increase in Import Cost by $\$ 1,000$ (about one standard deviation) increases the percentage of a typical firm's inputs of foreign origin by 16 percentage points (about 0.43 times the standard deviation units of Imports) using the base specification (column 1), and 21 percentage points (about 0.56 times the standard deviation units of Imports) using the full specification (column 6).

Income and firm-size show a positive and significant relationship with imports. This is not surprising as more developed economies and larger firms tend to be more involved in international trade.

Table 2 repeats the Table 1 estimations by including a quadratic term for the import cost variable. We find a significant non-linear (convex) relationship between Import Cost and Imports implying that while the relationship between the Imports and Import Cost is always negative in our sample, it is much more negative at lower values of Import Cost. For example, a unit increase in import cost reduces the share of imported inputs by 0.037 percentage points at the highest value of import cost in our sample and by 0.025 percentage points at the lowest value of import cost. This non-linear relationship may be because when the import cost is high, firms import proportionately more essential inputs that cannot be squeezed with rising import costs. Another possibility is that the fixed costs of increasing imports imply a substantial reduction in the cost of importing before imports can increase. Either way, accounting for the stated nonlinearity is important for a proper identification of the relationship between foreign inputs and import costs. 


\section{Conclusion}

Recent evidence on the importance of imported inputs for productivity and growth of firms begets an important question for policy makers - what policy measures, if any, can help firms to better access foreign inputs? Using a sample of manufacturing firms across 26 developing countries we find that the costs to import appears to have a strong negative effect on the percentage of firm's inputs that are of foreign origin and this is particularly strong at relatively low levels of import costs. Hence, policies that lower the cost of importing are likely to boost the use of foreign inputs and therefore growth. 


\section{References}

[1] Amin, M. and A. Islam (2014), “Imports of Intermediate Inputs and Country Size,” Applied Economic Letters, forthcoming.

[1] Amiti, M. and J. Konings (2007), “Trade Liberalization, Intermediate Inputs, and Productivity: Evidence from Indonesia,” American Economic Review, 97(5):1611-1638.

[2] Bernard, A. B., J. B. Jensen, S. J. Redding and P. K. Schott (2007), "Firms in International Trade,” Journal of Economic Perspectives, 21:105-30.

[3] Gibson, M. J., and T. A. Graciano (2011), "Costs of Starting to Trade and Costs of Continuing to Trade,” Mimeograph, Washington State University.

[4] Halpern, L., M. Koren, and A. Szeidl (2009), “Imported Inputs and Productivity,” CeFiG Working Paper No. 8, Budapest: Center for Firms in the Global Economy.

[5] Seker, M. (2012), “Importing, Exporting, and Innovation in Developing Countries,” Review of International Economics, 20(2) 299-314.

[6] Wagner, J. (2012), “International Trade, Firm Performance: A Survey of Empirical Studies since 2006,” Review of World Economics/Weltwirtschaftliches Archiv, 148(2), 235-267. 


\section{Figure 1}

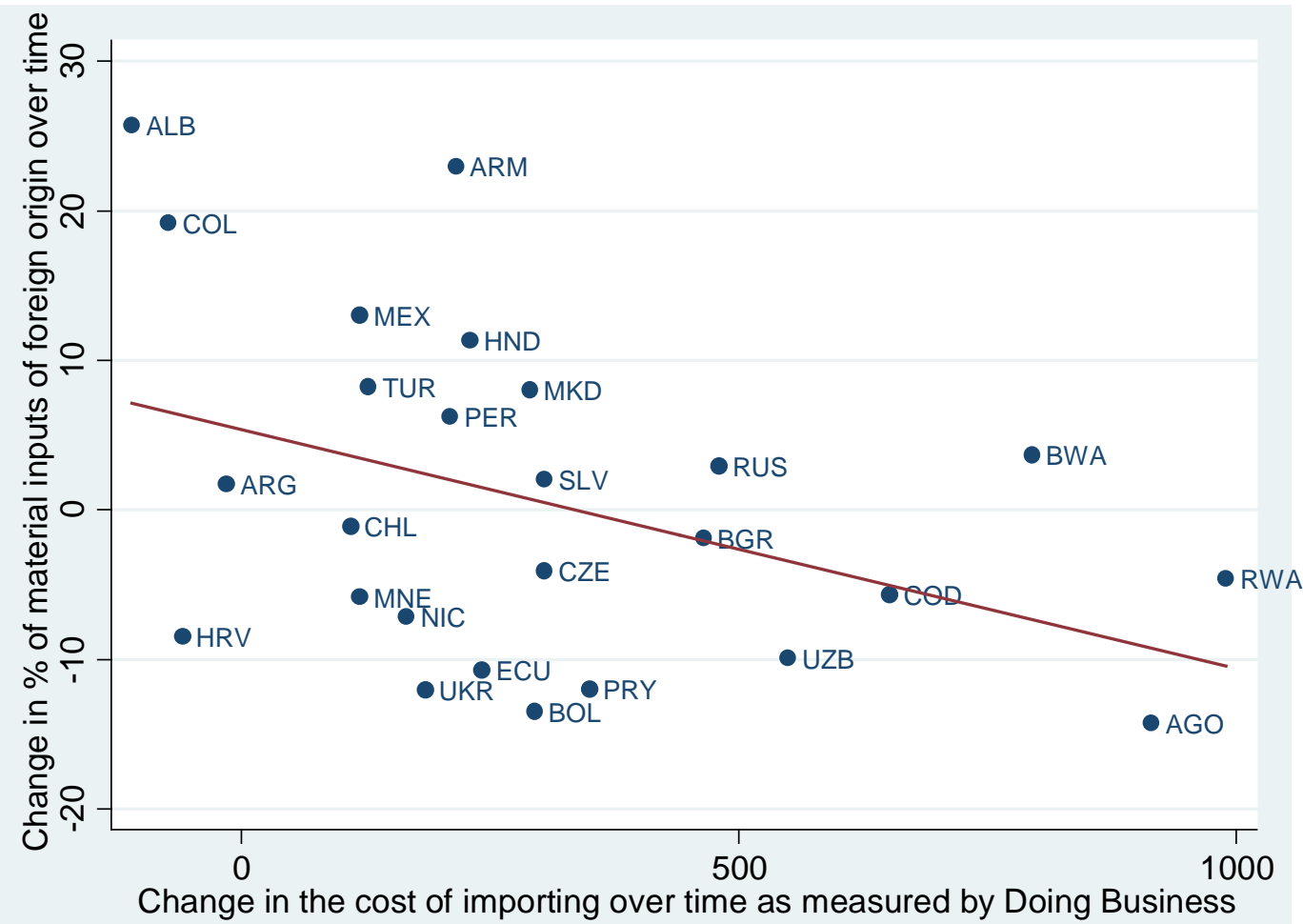

The negative relationship shown is statistically significant at less than the 5 percent level. 
Table 1: Base regression results (controlling for country fixed effects)

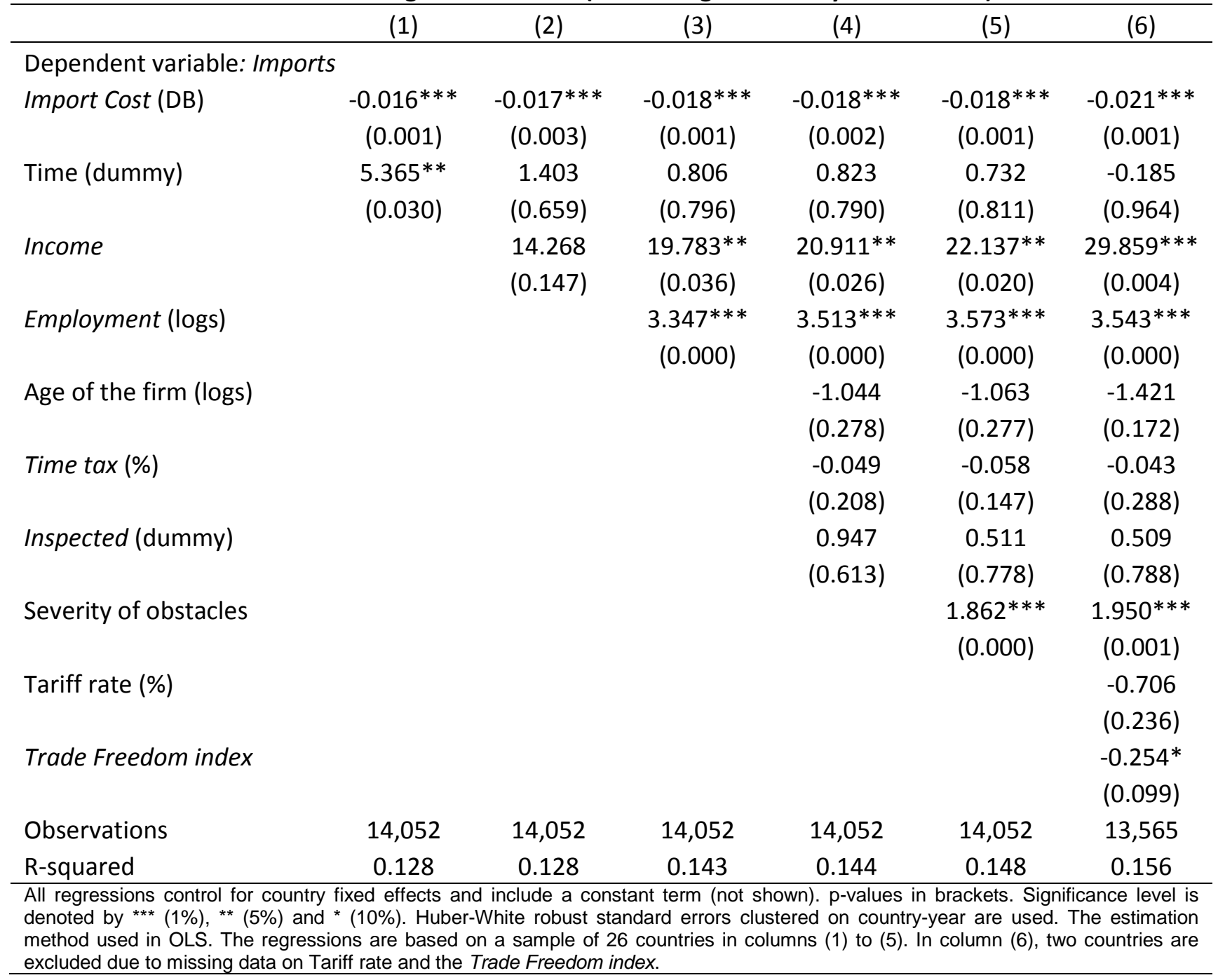




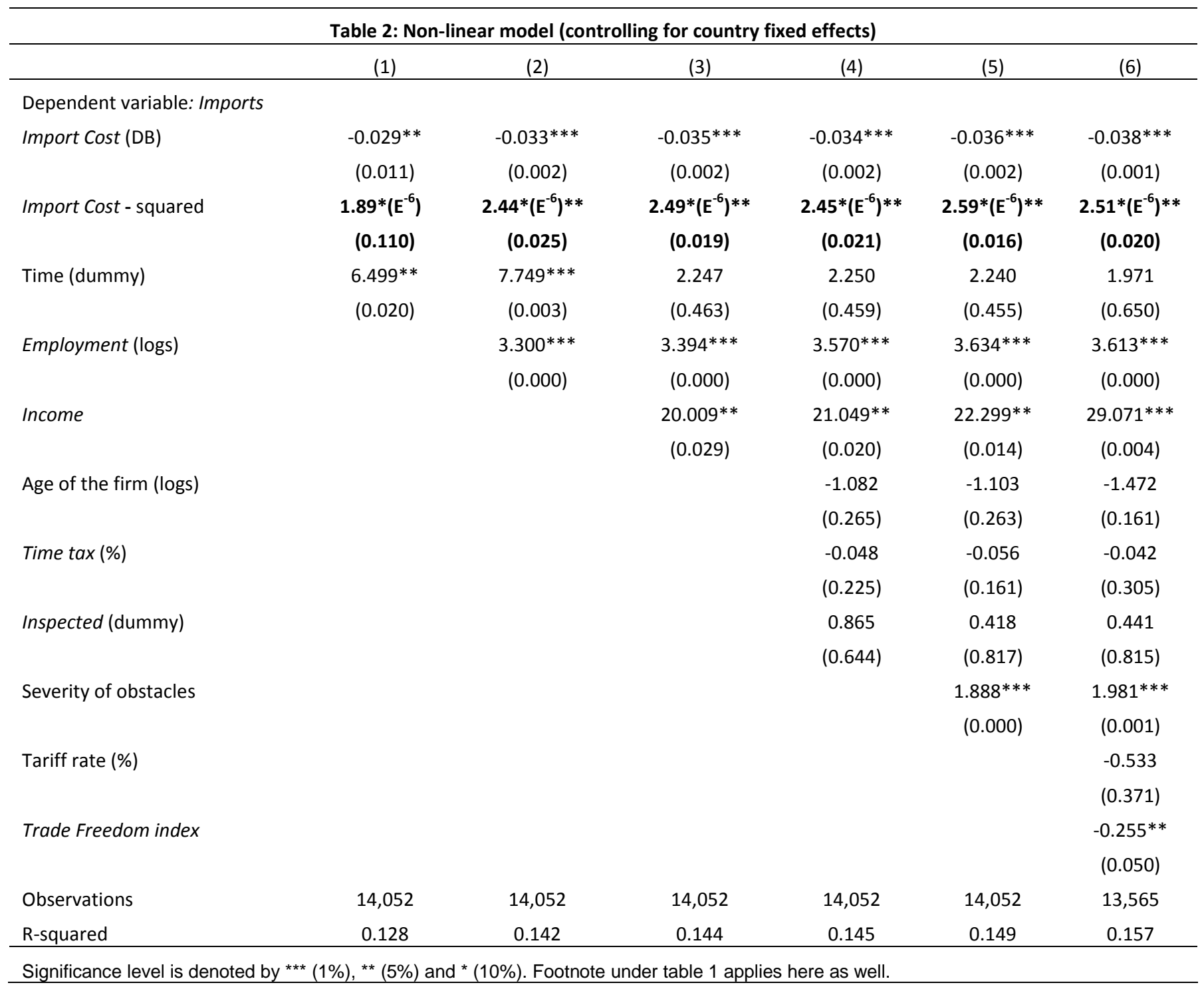

